\title{
Electricity intensities of the OECD and South Africa: A comparison
}

\author{
Roula Inglesi ${ }^{1, *}$, James N. Blignaut ${ }^{2}$ \\ ${ }^{1}$ Department of Economics, University of Pretoria, Pretoria, South Africa \\ 2 Department of Economics, University of Pretoria, Pretoria, South Africa \\ * Corresponding author. Tel: +27 12 4204504, Fax: +27 865 695811, E-mail: roula.inglesi@up.ac.za
}

\begin{abstract}
Improving a country's electricity efficiency is considered one of the important ways to reduce a country's greenhouse gas emissions. This paper's main purpose is to compare the South African total electricity intensity with these of the OECD members, in order to establish a sense of South Africa's relative performance. These results will assist in ascertaining possible scope for improvement, and if such exits, determining in which of the industrial sectors. To calculate the electricity intensities, we defined them as the ratio of electricity consumption to total output and then compare the South African with their OECD counterparts in total and disaggregated levels. For some of the countries the data were not sufficient for analysis over a long time period. Our results indicate that South Africa not only suffers from higher total and sectoral intensity levels but also the gap between them is increasing at an alarming rate. We conclude that for South Africa to improve its industrial competitiveness and achieve its stated commitments to the reduction of greenhouse gas emissions, it will have to improve its efficiency. This is likely to be achieved only through a concerted sector-specific approach.
\end{abstract}

Keywords: Electricity, Intensity, South Africa, OECD, Comparative Analysis

\section{Introduction}

Improving the electricity efficiency of a country is an important step towards decreasing greenhouse gas emissions originating from fossil fuel based electricity generation and consumption. From a policy-making perspective, the studying of efficiency is significant since it is a measure that combines the electricity consumption with the economic output [1] and the comprehension of the behavior of electricity demand under economic structural changes is imperative [2]. In the past a large number of studies were conducted to identify the dynamics, determinants and characteristics of electricity intensity in developed and developing economies $[3,4,5,6]$, resulting in showing the electricity intensity increases, as a consequence of economic growth and decreases as the economy progresses, shifting to services-based sectors [7]. This trend can be compared to the famous environmental Kuznetscurve $[8,9]$, but applied to the electricity intensity.

Here we seek to answer the question whether South Africa follows the international trends regarding electricity intensity. We do this by conducting a comparison between South Africa's national and sectoral electricity intensities and the equivalents thereof of the member countries of Organisation for Economic Co-operation and Development (OECD).

The main reason for focusing on the electricity intensity and not on energy in general lies with the fact that the energy sector is too diverse for comparative analysis. For instance, the intensity trends in the use of petrol are dependent on whether the country is an oil-producer or not. On contrary, the OECD members and South African electricity sectors present similar characteristics, especially regarding their generation, which is regulated and controlled by a monopolist. Hence, we argue that energy intensities would not be a comparable indicator between the selected groups of countries.

On a national level, the exercise will indicate whether there is scope for improvement. Furthermore, the analysis on a sectoral level will be beneficial because, firstly, it is imperative 
to understand the differences in economic and energy characteristics of each sector [10]; and secondly, not all the economies produce the same goods and service in the same proportion [11].

The next section of this paper will introduce the meaning of electricity efficiency and intensity as well as the current situation of electricity efficiency in South Africa. This is followed by the description of the data used and an international electricity intensity comparison on both a national and a disaggregated level. Finally, we conclude with a discussion on the findings.

\section{Background}

Following the political transition in 1994, the new democratically elected South African government considered energy issues as of great importance for the economic development of the country. In the first White Paper on Energy Policy [12] energy efficiency was mentioned among the cross-cutting issues. More specifically for the industrial and commercial sectors, the government committed itself to the following:

- $\quad$ Promotion of energy efficiency awareness

- $\quad$ Encouragement of the use of energy efficiency practices

- $\quad$ Establishment of energy efficiency standards for commercial buildings

- $\quad$ Monitoring the progress

While progress on these was slow due to pressing socio-economic and development considerations, the South African Department of Minerals and Energy released its first Energy Efficiency Strategy in 2005 [13]. The purpose of the Strategy was to provide a policy framework toward affordable energy for all and diminish the negative consequences of the extensive energy use in the country. Its national target was to improve electricity efficiency by $12 \%$ by 2015 . The document, however, had limited impact to date and is currently being revised.

Fig. 1 shows the economy-wide electricity intensity and its growth for the period 1994-2006. Total electricity intensity showed a sharp upward trend until 2004. The period 2005-2006 was characterised by a notable decrease in the electricity intensity of $8.4 \%$ Firstly, the electricity prices increased by 182\% in 2003 and it was highly impossible for the electricity consumers to react and change their behaviour in the short-run. Hence, the drop in electricity intensity (caused by a decrease in electricity consumption) might be considered the lagged impact of the high increase in electricity prices. Also, from a policy perspective, the first Energy Efficiency Strategy in 2005 [13] might also be the cause of a decrease in 2005/06.

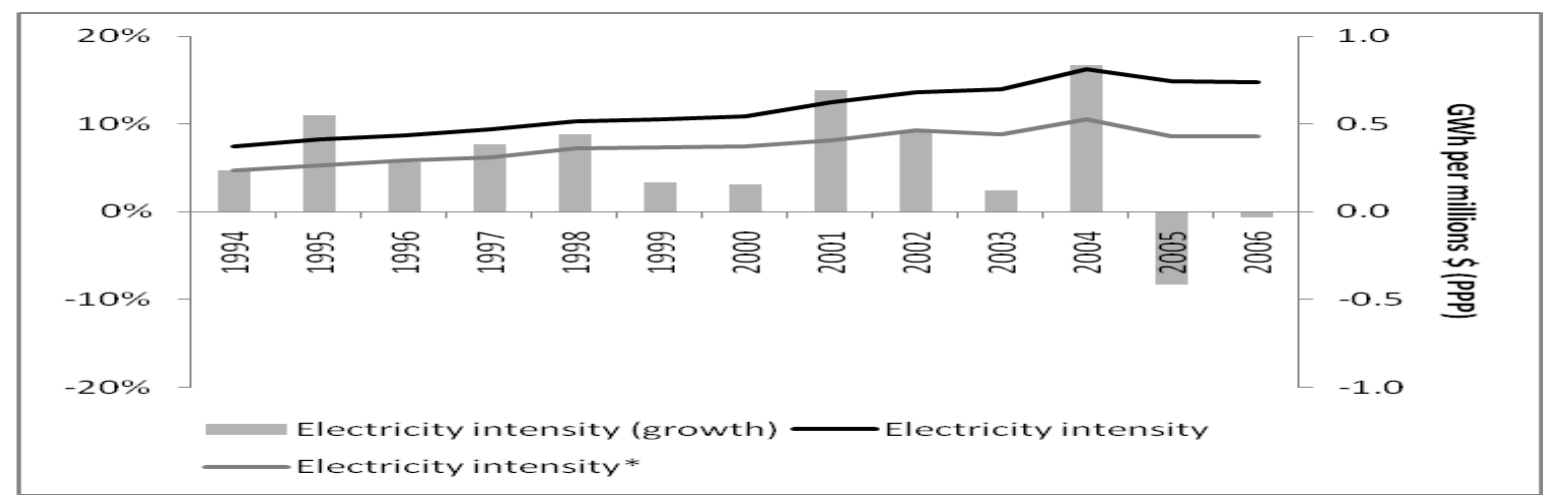

Fig. 1: Electricity intensity and its growth in South Africa: 1994 to 2006

*excluding residential, commercial and non-classified electricity consumption 
Sources: Authors' calculations based on IMF [14] and OECD [15]

However, if the industrial, transport, and agriculture sectors' electricity consumption is included only in the calculation, a lower intensity is observed with the growth not being as steep as before. Large inter-sectoral variations, however, exist ${ }^{1}$.

Given this general information, how does South Africa compare, both on a national as well as sectoral level, with the OECD countries? We turn to this next.

\section{Methodology and data}

Several studies concerned with inter-country comparison of electricity intensities have been conducted [16, 17, 18, and 19]. These studies have, however, encountered certain difficulties, such as the heterogeneous definition of the variables as well as the diverse interpretations of the ratios calculated. We tried to avoid these problems by estimating the electricity intensities for each country using the same definition (i.e. electricity consumption/gross domestic product (GDP)) and the same dataset. We selected the OECD members because this group provides us with a wide spectrum of developed and developing countries with different economic and energy-related characteristics, but with its data and definitions being consolidated under one umbrella organisation. This limits the risk of data inconsistencies.

The data for electricity consumption (total and sectoral) were obtained from the OECD's Energy balances for OECD countries [20] and for South Africa from Energy balances for non-OECD countries [15]. The national GDP data (in current prices), the consumer price index (base year 2000) and the Power Purchasing Parity (PPP) adjusted real exchange rate values for all the countries were derived from the World Economic Outlook April 2010 of the International Monetary Fund (IMF). The disaggregated data for output for OECD members were derived from the STAN Database for Structural Analysis of OECD.

\section{Results of comparative analysis}

In 1980 South Africa's electricity intensity was substantially lower than that of OECD countries (see Fig. 2). This is to be expected to some extent given the high level of welfare enjoyed by a minority of people based on an industrial sector that services only a few with limited focus on exports at that point in time. Given the country's skew income distribution, a skew electricity usage was also presented: the higher income sectors were the most electricity intensive, too.

The country's electricity use rose sharply since the early 1990s with the abolishment of sanctions, the internationalisation of the markets to international trade, and the more stable economic and political situation after its first democratic elections in 1994. Hence, after 1994, the country's exports of electricity have been increased as well as the growth of the economy. These facts led to a strong impact on electricity use and since the 1990s, however, the electricity intensity in South Africa kept rising at an alarming rate $(0.329 \mathrm{GWh} / \mathrm{mil}$ \$ adj PPP in 1990 to $0.713 \mathrm{GWh} / \mathrm{mil}$ \$ adj PPP in 2007) and currently far exceeds that of the OECD countries (0.318 GWh/ mil \$ adj PPP in 1990 to $0.3422 \mathrm{GWh} / \mathrm{mil}$ \$ adj PPP in 2007) with no sign of any change.

\footnotetext{
${ }^{1}$ Data available upon request
} 


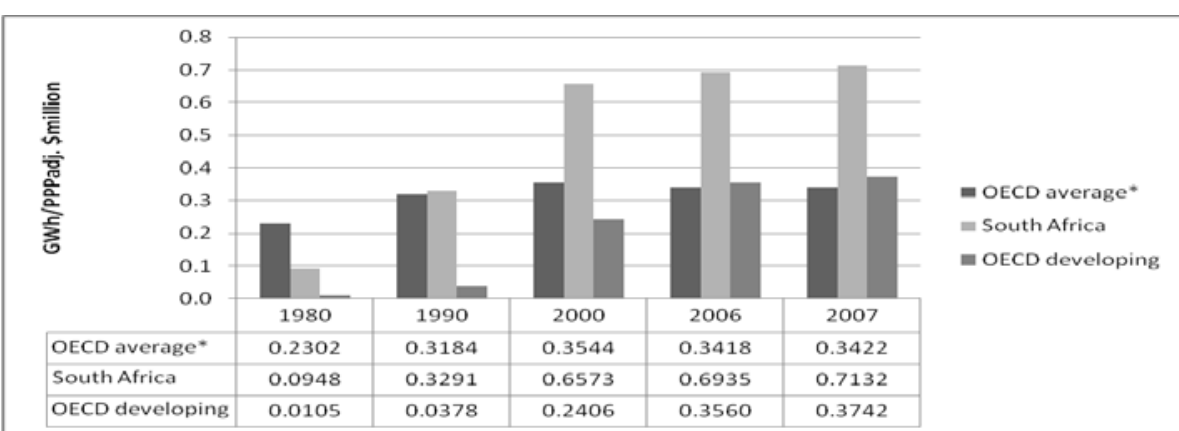

Fig. 2: Evolution of electricity intensity: Average OECD and South Africa

* It excludes Czech Republic, Slovak Republic and Turkey due to lack of data of 1980 and 1990.

Source: Authors' calculations based on IMF [24] and OECD [25, 28]

In the same figure, we extracted the developing economies of the OECD group (Hungary, Poland, Mexico and Turkey) and weight their average against South. Its electricity intensity was higher than that of the average of the OECD developing economies, throughout the years. Following this analysis, we disaggregate the OECD average to examine how South Africa compares with the OECD countries individually over the study period. The economy-wide percentage change of electricity intensity for the period 1990 to 2007 as well as the electricity intensity of 2007 for the OECD members and South Africa is presented in Fig. 3.

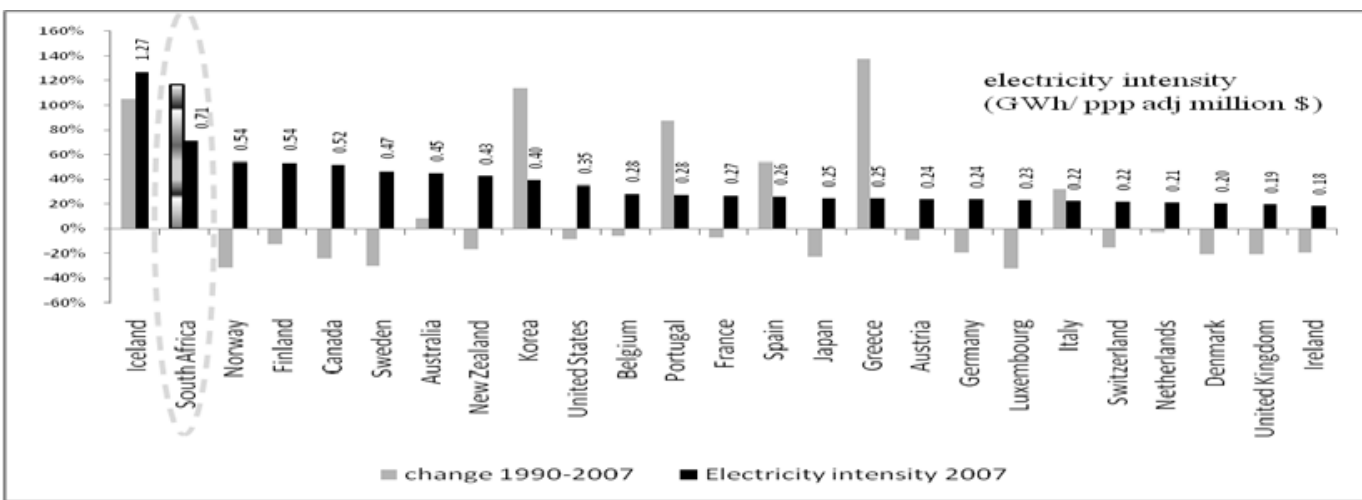

Fig. 3a: Electricity intensity in 2007 and its growth (1990 to 2007) for South Africa and OECD members ${ }^{2}$

Source: Authors' calculations based on IMF [14] and OECD [15, 20].

From Fig. 3a it is clear that South Africa has shown an increase in electricity intensity of $117 \%$ over the study period. This is in sharp contrast to the average of the OECD members which was only $10.09 \%$. Only the Mediterranean countries (Spain, Greece, Portugal and Italy) as well as Korea and Iceland experienced an increase in their electricity intensities. Both their output and electricity consumption increased substantially, but the increase in consumption was higher than the growth in output and therefore their intensities experienced such sharp increases.

A further remarkable trend can be observed from Fig. 3a. There is a statistically significant negative, or inverse, relationship between the level of electricity intensity in 1990 and its

\footnotetext{
${ }^{2}$ It should be noted that Poland, Hungary, Mexico and Turkey were outliers (hence, excluded from the figure) with changes in electricity intensity for the examined period of 382\%, 401\%, 493\% and more than 1,000\% (from 0.0006 in 1990 to 0.723 in 2007) respectively. Also, the Czech and Slovak Republics were excluded due to lack of data points for 1990
} 
growth over the study period ${ }^{3}$. This implies and that the higher the electricity intensity of a country in 1990 was, generally speaking, the more negative its growth was from 1990 to 2007. Countries such as Norway, Canada and Sweden, who were the most electricity intensive in 1990, were the ones that managed to decrease their intensity of electricity usage meaningfully, namely by $32 \%, 24 \%$ and $30 \%$ respectively. On the contrary, Italy, Portugal and Greece with the lowest intensities in 1990, raised them by $33 \%$, $88 \%$ and $138 \%$ respectively. South Africa, however, does not fit this trend well. It had an average electricity intensity in 1990 and yet it had the second highest increase (after Greece) of its intensity (117\%). The country, therefore, does not follow international trends in this regard.

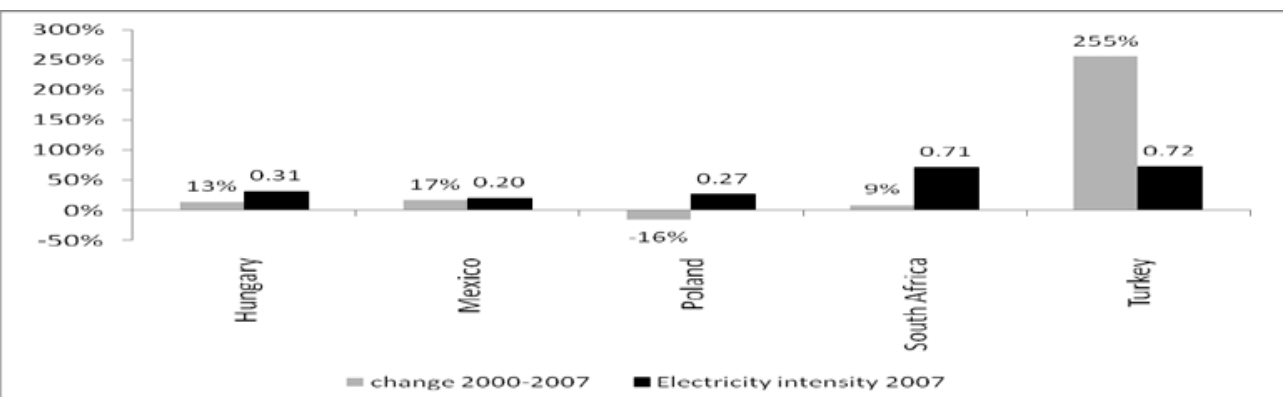

Fig. $3 b$ Electricity intensity in 2007 (in GWh. \$million (PPP adj)) and its growth: 2000-2007 for South Africa and OECD developing countries.

Source: Authors' calculations based on IMF [14] and OECD [15, 20].

Figure 3b presents a rather dismal picture for South Africa's electricity intensity in comparison with developing countries of the OECD. Its intensity was more than three times higher than this of Hungary, Mexico and Poland and at the same levels as Turkey. However, its growth for the period 2000 to 2007 was significantly less than this of Turkey (255\%) and less than Hungary's and Mexico's (13\% and 17\%). However Poland managed to reduce its electricity intensity by $16 \%$ for the same period.

The results from Fig. 3 clearly indicate that South Africa's electricity intensity was not only higher than the majority of OECD countries in absolute terms (for 2007), but also showed excessive increase for the period 1990 to 2007 compared to the rest of the countries in the studied group. The next question that arises is whether this trend holds for all the economic sectors of South Africa.

To investigate the differences among industrial sectors, Table 1 presents the sectoral electricity intensities for South Africa and OECD average in 2006 and their differences. The majority of the South African sectors are more electricity intensive than the OECD average. Only four out of thirteen were more efficient than OECD and they are 'construction', 'food and tobacco', 'machinery' and 'transport equipment'. The order of magnitude in which they outperformed their OECD counterparts is on average 150.5\%. This is in stark contrast to the degree in which the sectors whose intensity levels are worse than their OECD counterparts, namely $980.7 \%$ - a 6.5-fold difference.

\footnotetext{
${ }^{3}$ The results of the chi-square test and the Bartlett chi-square test are statistically significant confirming the existence of such relationship (chi-square $=3.63(p$-value $=0.057)$ and Bartlett chi-square=3.41 $(p$-value=0.065)
} 
Table 1: Sectoral electricity intensities in 2006 and output share: South Africa and OECD (Intensity: GWh/millions \$ adj PPP; output: percentage)

\begin{tabular}{|c|c|c|c|c|c|c|}
\hline \multirow[b]{2}{*}{ Sectors } & \multicolumn{2}{|c|}{ South Africa } & \multicolumn{2}{|c|}{ OECD } & \multicolumn{2}{|c|}{ Differences } \\
\hline & Intensity & Output & Intensity & Output & Intensity & Output \\
\hline $\begin{array}{l}\text { Agriculture and } \\
\text { forestry }\end{array}$ & 0.316 & $6.00 \%$ & 0.016 & $4.00 \%$ & $1875.0 \%$ & $50.00 \%$ \\
\hline Basic metals* & 1.095 & $7.10 \%$ & 0.111 & $5.10 \%$ & $886.5 \%$ & $39.22 \%$ \\
\hline $\begin{array}{l}\text { Chemical and } \\
\text { petrochemical }\end{array}$ & 0.203 & $16.30 \%$ & 0.034 & $15.20 \%$ & $497.1 \%$ & $7.24 \%$ \\
\hline Construction & 0.002 & $10.50 \%$ & 0.087 & $16.60 \%$ & $-97.7 \%$ & $-36.75 \%$ \\
\hline Food and tobacco & 0.021 & $12.00 \%$ & 0.023 & $8.30 \%$ & $-8.7 \%$ & $44.58 \%$ \\
\hline Machinery & 0.005 & $2.90 \%$ & 0.028 & $15.00 \%$ & $-82.1 \%$ & $-80.67 \%$ \\
\hline $\begin{array}{l}\text { Mining and } \\
\text { quarrying }\end{array}$ & 0.634 & $14.60 \%$ & 0.026 & $3.00 \%$ & $2338.5 \%$ & $\begin{array}{c}386.67 \\
\%\end{array}$ \\
\hline $\begin{array}{l}\text { Non-metallic } \\
\text { minerals }\end{array}$ & 0.524 & $1.60 \%$ & 0.02 & $2.00 \%$ & $2520.0 \%$ & $-20.00 \%$ \\
\hline $\begin{array}{c}\text { Paper, pulp and } \\
\text { printing }\end{array}$ & 0.207 & $2.80 \%$ & 0.021 & $5.50 \%$ & $885.7 \%$ & $-49.09 \%$ \\
\hline Textile and leather & 0.067 & $2.50 \%$ & 0.01 & $1.90 \%$ & $570.0 \%$ & $31.58 \%$ \\
\hline Transport equipment & 0.003 & $9.80 \%$ & 0.004 & $10.50 \%$ & $-25.0 \%$ & $-6.67 \%$ \\
\hline $\begin{array}{l}\text { Transport sector } \\
\text { Wood and wood }\end{array}$ & 0.089 & $12.50 \%$ & 0.013 & $11.20 \%$ & $584.6 \%$ & $11.61 \%$ \\
\hline products & 0.069 & $1.40 \%$ & 0.027 & $1.50 \%$ & $155.6 \%$ & $-6.67 \%$ \\
\hline
\end{tabular}

* Includes 'iron and steel' and 'non-ferrous metals'

'Basic metals' have the highest electricity intensity in both South Africa and the OECD countries. Comparatively speaking, however, South Africa's 'basic metals' sector was significantly more intensive (886\%) than the OECD average before adjusting it to its respective size (or contribution to output) and 644\% thereafter. The most efficient sector was 'construction', mainly due its high labour intensity and lower use of electricity-demanding technologies. On top of that the South African 'construction' sector was significantly more efficient than the OECD average. Why the 'construction' sector is more efficient compared to the rest can only be speculated about. This is due to a number of inter-linked factors; one of them being the labour intensity of the sector. This is since all the South African sectors are more labour intensive in comparison with the OECD countries, especially "construction", which is $600 \%$ higher than its OECD equivalents. The difference of the rest of the South African sectors to the OECD ones is in the range of $100-300 \%$. The weighted difference shows that the South African intensity was 156\% lower than the OECD average.

While most electricity intensive South African sectors, i.e. 'basic metals' and 'non-metallic minerals' present high differences with the OECD average (644\% and 2517\%), 'Mining and quarrying' does not follow suit. The South African electricity intensity was 2305\% higher than the OECD average, however, considering that the South African mining sector is a dominant one for the economy (14.6\%) while a very small proportion of the OECD production (3\%), the difference albeit is still very meaningful. 


\section{Conclusions}

The study of electricity efficiency has recently become an important topic for two main reasons. Firstly, it is highly linked to negative consequences of greenhouse gas emissions and secondly it is a measure that combines electricity use with economic output [1]. Our analysis shows that South Africa's electricity intensity was at a level much higher than that of the OECD countries and the gap between South Africa and OECD is also increasing at an alarming rate. While alarming, it points towards scope for improvement necessary if South Africa is to remain competitive in trade regimes including carbon trading considerations with its OECD counterparts [21, 22].

South Africa has shown an increase in electricity intensity over the study period of $117 \%$ more than doubling its electricity intensity from $0.32 \mathrm{GWh} /$ millions \$ adj PPP to 0.71 $\mathrm{GWh} / \mathrm{millions}$ \$ (PPP). This is in sharp contrast to the average of the OECD members, which was only $10.09 \%$. From our results, nine out of thirteen South African sectors are more intensive than their OECD equivalents, and by a considerable margin. Although 'basic metals', 'mining and quarrying' and 'non-metallic minerals' were the most electricity intensive sectors, these sectors presented the greatest gap with those of OECD being more efficient.

In summary, it became apparent that for South Africa to reduce its electricity intensity it has to either reduce its electricity usage or increase its production while keeping its electricity consumption stable. The lack of appropriate policies and the low and stable prices of electricity in the country for the studied period might be the main reasons for the results. South African producers were not concerned for electricity efficiency given the relatively low price levels of electricity over the period. Progress can be made by a concerted industrial policy to enhance the use and development of electricity efficient appliances. Electricity price reform, such as what has been recently announced, whereby the electricity price level is significantly increased in conjunction with block rate tariffs that charges a higher rate to those that consume more, is also vital. A nation-wide demand-side management program is also essential in the wake of these results in order to improve efficiencies.

\section{References}

[1] B. Liddle, Electricity intensity convergence in IEA/OECD countries: Aggregate and sectoral analysis, Energy Policy 37, 2009, pp. 1470-1478.

[2] A. Markandya, S. Pedroso-Galinato, \& D. Streimikiene, Energy intensity in transition economies: Is there convergence towards the EU average?, Energy Economics 28, 2006, pp. 121-145.

[3] X. Zhao, C. Ma, \& D. Hong, Why did China’s energy intensity increase during 19982006: Decomposition and policy analysis, Energy Policy 38, 2010, pp. 1379-1388.

[4] M. Mendiluce, I. Pérez-Arriaga, \& C. Ocaña, Comparison of the evolution of energy intensity in Spain and in the EU15. Why is Spain different?, Energy Policy 38, 2010, pp. 639-645.

[5] F.I. Andrade Silva \& S.M.G. Guerra, Analysis of the energy intensity evolution in the Brazilian industrial sector-1995 to 2005, Renewable and Sustainable Energy Reviews 13, 2009, pp. 2589-2596. 
[6] P. Tiwari, An analysis of sectoral energy intensity in India, Energy Policy 28, 2000, pp. 771-778.

[7] K. Medlock III, \& R. Soligo, Economic Development and End-Use Energy Demand, The Energy Journal 22, 2001, pp. 77-106.

[8] S.E. Gergel, E.M. Bennett, B.K. Greenfield, S. King, C.A. Overdevest, \& B. Stumborg, A Test of the Environmental Kuznets Curve Using Long-Term Watershed Inputs, Ecological Applications14, 2004, pp. 555-570.

[9] D. Baker, The Environmental Kuznets Curve, The Journal of Economic Perspectives 17, 2003, pp. 226-227.

[10]R. Inglesi, \& J.N. Blignaut, Estimating the demand elasticity for electricity by sector in South Africa", Putting a price on carbon: Economic instruments to mitigate climate change in South Africa and other developing countries. Energy Research Center, University of Cape Town, 2010, pp. 65.

[11]C.L. Weber, Measuring structural change and energy use: Decomposition of the US economy from 1997 to 2002, Energy Policy 37, 2009, pp. 1561-1570.

[12] Department of Minerals and Energy (DME). 1998, White Paper on the Energy Policy of the Republic of South Africa, Department of Minerals and Energy, Pretoria.

[13]Department of Minerals and Energy (DME). 2005, Energy Efficiency Strategy of the Republic of South Africa, Department of Minerals and Energy, Pretoria.

[14] International Monetary Fund (IMF). 2010, World Economic Outlook April 2010, International Monetary Fund (IMF), Washington D.C., USA.

[15] Organisation for Economic Co-operation and Development (OECD). 2009, Energy balances for non-OECD countries, OECD , Paris, France.

[16]L. Schipper, M. Ting, M. Khrushch, \& W. Golove. The evolution of carbon dioxide emissions from energy use in industrialized countries: an end-use analysis, Energy Policy. 25, 1997, pp. 651-672.

[17]Economic Commission for Europe (ECE). 1996, Worldwide Energy Conservation Handbook, Energy Conservation Center, Tokyo.

[18]Energy Information Administration (EIA). 1999, Energy Efficiency page: Defining Energy efficiency and its measurement. Available at: http://www.eia.doe.gov/emeu/efficiency/ee_ch2.htm

[19]D. Bosseboeuf, B.Chateau, \& B. Lapillonne, B. Cross-country comparison on energy efficiency indicators: the on-going European effort towards a common methodology, Energy Policy. 25, 1997, pp. 673-682.

[20] Organisation for Economic Co-operation and Development (OECD). 2009, Energy balances for OECD countries, OECD , Paris, France.

[21]J.N. Blignaut, R.M. Mabugu, \& M.R. Chitiga-Mabugu, Constructing a greenhouse gas emissions inventory using energy balances: the case of South Africa: 1998, Journal of energy in Southern Africa16, 2005, pp.105-116.

[22] J. Van Heerden, R. Gerlagh, J.N. Blignaut, M. Horridge, S. Hess, R. Mabugu, \& M. Mabugu, Searching for triple dividends in South Africa: Fighting $\mathrm{CO}_{2}$ pollution and poverty while promoting growth, The Energy Journal 27, 2006, pp.113-142. 